(2) Open Access Full Text Article

REVIEW

\title{
Improving access to home phototherapy for patients with psoriasis: current challenges and future prospects
}

\author{
This article was published in the following Dove Press journal: \\ Psoriasis: Targets and Therapy \\ 18 May 2016 \\ Number of times this article has been viewed
}

\section{Sylvie M Franken \\ Carlijn L Vierstra \\ Thomas Rustemeyer \\ Department of Dermatology, VU University Medical Centre, Amsterdam, the Netherlands}

Correspondence: Sylvie M Franken Department of Dermatology, VU University Medical Centre, De Boelelaan III8, 108IHV Amsterdam, the Netherlands Fax +3 I 204440148 Email s.franken@vumc.nl
Introduction: Although the treatment burden for phototherapy in the outpatient setting is considerable, prescription of home-based phototherapy has not been instigated. Home-based phototherapy seems more patient friendly in terms of avoiding the thrice-weekly hospital visits. So why are most treatments still given in a hospital setting? Is home-based treatment less effective? Are there financial barriers? Is the treatment not available? To answer these questions, a literature search was done.

Methods: A literature search of PubMed, Embase, and Cochrane Library databases was performed, using the search terms "psoriasis" and "phototherapy". Selection was based on two rounds; the first round involved screening the title and abstract of all records and second involved evaluating the full text of the remaining articles for eligibility according to inclusion and exclusion criteria.

Results: In total, 23 publications were included with consensus of both researchers. Overall, the patients reported being very satisfied with home-based phototherapy. Results regarding effectivity in terms of improvement from disease severity and in quality of life were variable but generally positive. Reasons for reluctance varied from medicolegal and social aspects to lack of reimbursement and unfamiliarity on the side of the prescriber.

Conclusion: In the treatment for psoriasis, home-based phototherapy is as effective and safe as phototherapy in an outpatient setting. Patients were more satisfied with home-based phototherapy. Factors that negatively influence the prescription of or choice for home-based phototherapy can be summarized in terms of lack of control, lack of knowledge, and lack of a good reimbursement system.

Keywords: psoriasis, phototherapy, UVB, home-based, effectiveness, burden, costs, access

\section{Introduction}

Phototherapy is a widely used and effective treatment for moderate-to-severe psoriasis. Many studies have proven the therapeutic effect of the different phototherapy modalities for psoriasis: psoralen with ultraviolet (UV) A, broad-band (BB)-UVB, and narrow-band (NB)-UVB.

Although phototherapy was primarily used in an inpatient (Goeckerman treatment) setting, the outpatient setting later prevailed. Patients could stay at home while undergoing treatment and fulfill most of their usual day-to-day routine. Patients come two to three times a week to the hospital to undergo their treatment. A big step forward has been the inpatient setting, but it causes a different disadvantage. Patients need to travel to the hospital two to three times a week, mostly during business hours, which is costly and difficult to fit into daily life. 
In 1979, Larkö and Swanbeck ${ }^{1}$ reported the first use of home phototherapy, using BB-UVB. Home treatment brought certain advantages: less travel inconvenience for patients and more control on their own schedule. Instead of the mandatory hospital visits two to three times a week, patients could undergo their treatment at home. A great step for patients with psoriasis in a society that is individualizing, and in which the schedule and autonomy of the patient has become increasingly important.

Home UV treatments have further been developed; several studies were performed with low-dose UV treatment and, in particular, NB-UVB treatment. ${ }^{2,3}$ This treatment modality, however, has not become the first choice of health professionals. Outpatient UV-treatment seems to be the standard treatment modality. In this review, we try to explore the reasons for this. What is the effectivity of homebased phototherapy? What are the factors that influence the prescription of home-based phototherapy?

\section{Methods}

This review is based on literature searches that were performed in PubMed, Embase, and Cochrane Library databases to ascertain the effectivity of home-based phototherapy vs hospital-based phototherapy and the factors that influence its prescription.

\section{Search strategy}

Literature searches for relevant publications were conducted on April 22, 2015.

\section{Medline via PubMed}

The query used was ("Psoriasis"[Mesh] OR psoria*[tiab] OR psoria*[ot]) AND ("Phototherapy"[Mesh:NoExp] OR "Ultraviolet Therapy"[Mesh] OR phototherap*[tiab] OR actinotherap*[tiab] OR ((ultraviolet[tiab] OR uv[tiab] OR uvb[tiab] OR uva[tiab] OR photoradiat*[tiab] OR light[tiab]) AND (therap*[tiab] OR treatment*[tiab])) OR phototherap*[ot] OR actinotherap*[ot] OR ((ultraviolet[ot] OR uv[ot] OR uvb[ot] OR uva[ot] OR photoradiat*[ot] OR light[ot]) AND (therap*[ot] OR treatment*[ot]))) AND (home[tiab] OR home [ot]).

\section{Embase}

We used the following query: ("psoriasis"/exp OR psoria*:ab,ti) AND ("phototherapy"/de OR "phototherapy device"/de OR phototherap*:ab,ti OR actinotherap*:ab,ti OR (ultraviolet:ab,ti OR uv:ab,ti OR uvb:ab,ti OR uva:ab,ti OR photoradiat*:ab,ti OR light:ab,ti AND (therap*:ab,ti OR treatment*:ab,ti))) AND (home:ab,ti)).

\section{Cochrane Library}

The search included trials, Cochrane reviews, method studies, economic evaluations, and technology assessments and used the following query: (psoria*:ti,ab,kw) AND (phototherap*:ti,ab,kw or actinotherap*:ti,ab,kw or ((ultraviolet:ti,ab,kw or uv:ti,ab,kw or uvb:ti,ab,kw or uva:ti,ab,kw or photoradiat*:ti,ab,kw or light:ti,ab,kw) and (therap*:ti,ab,kw or treatment*:ti,ab,kw))) AND (home:ti,ab,kw).

\section{Inclusion and exclusion criteria}

The inclusion criteria for articles to determine effectivity were as follows: studies should have been original research, patients diagnosed with psoriasis, moderate-to-severe disease (or Psoriasis Area and Severity Index [PASI] score $\geq 10$ ), and studies about phototherapy at home, hospital, or clinic about the effectivity on disease severity and/or quality of life (QoL). Records were excluded if the study population had only mild or localized psoriasis (or PASI score $<10$ ), if there was no UVB involved in the study, or if there was concomitant use of systemic immunosuppressants.

For the factors that influence the prescription of homebased phototherapy, articles that were selected had studied patients with chronic skin diseases who underwent treatment with phototherapy at home, hospital, or clinic; exclusion criteria encompassed the following: not being prescribed home phototherapy, no UVB involved in the study, use of commercial tanning beds, the treatment indication was aesthetic or hyperbilirubinemia, and the record was not an original study.

\section{Results}

\section{Effectiveness of home-based phototherapy}

Abel $^{4}$ already pointed out in 1985 the difficulties in obtaining comparative data because of variation in treatment schedules, irradiation units, and criteria used to evaluate treatment response. A problem was also encountered in this work.

The first time that phototherapy treatment for psoriasis was given in the patient's home was by Larkö and Swanbeck in $1979 .{ }^{1}$ The effectivity of daily high-dose (1 minimal erythema dose [MED], increased by factor 1.4 every week) BB-UVB home-based phototherapy for patients with psoriasis was investigated. When skin lesions cleared, patients underwent maintenance therapy twice a week with the same device. Twenty out of 28 patients in the study population achieved complete clearance, but 25 experienced some degree of phototoxicity. Patients were biopsied prior to and after irradiation: no epidermal changes or increase in actinic elastosis was noted. 
Jordan et $\mathrm{al}^{5}$ investigated the modified Goeckerman treatment with a home-based BB-UVB light source. All 55 patients with psoriasis who completed the treatment program had complete clearance in $42-60$ UVB treatment sessions; no serious side-effects or phototoxicity was reported.

Paul et $\mathrm{al}^{3}$ had investigated the use of a low-intensity home-based phototherapy device. The device emitted in the range of 300-320 nm, including some UVA. In the group treated with the device designed for home-based phototherapy, only eight out of 20 patients had complete clearance of their psoriatic lesions, compared to 18 out of 20 patients using the standard outpatient UVB phototherapy device. In the group undergoing home treatment, however, a different protocol was used than in the group using standard UVB treatment. This resulted in a lower dose for the former group per treatment.

Feldman et $a l^{6}$ investigated the use of home-based BBphototherapy devices. A survey among 31 patients with psoriasis found that in the previous 2 years, the 22 patients who responded treated themselves 3.7 days a week for $\sim 6.2$ minutes. This correlated with the existing guidelines at that time. The mean control visit frequency was 4.5 months. Generally, respondents reported home-based UVB phototherapy to be very helpful for their psoriasis.

Cameron et $\mathrm{al}^{7}$ studied the clearance rate in patients with psoriasis and other photoresponsive diseases when treated with NB-UVB at home. Clearance or minimal residual activity (MRA) was reached with home-based phototherapy in 18 out of 30 patients with psoriasis after a mean number of 22.5 treatments. The self-reported erythema rates were higher in the home-based phototherapy group compared to the erythema rates found in the database of patients treated in an outpatient setting. It was concluded that the training of patients before undertaking home-based phototherapy should be improved.

Haykal and DesGroseilliers ${ }^{8}$ performed a survey among 25 patients with psoriasis. Twenty of them received homebased phototherapy. They concluded that all patients receiving home-based phototherapy were satisfied with their treatment, planned to continue with it, and would recommend it to other patients.

In 2009, Koek et al ${ }^{9}$ performed a randomized controlled trial of NB-UVB phototherapy given at home compared to the outpatient setting. They investigated the effectivity, QoL, burden of treatment, and patients' satisfaction. The outcome measures regarding the effectivity were the proportions of patients reaching at least $50 \%, 75 \%$, or $90 \%$ decrease from baseline SA (self-administered)-PASI/PASI score, termed the
PASI/SA-PASI 50/75/90 score. There were no statistically significant differences in these scores between both groups, but only small differences in SA-PASI 50/75/90 scores favoring home-based phototherapy and small differences in PASI 50/75/90 scores favoring phototherapy in an outpatient setting. The QoL was equally improved in both groups. The burden of treatment, however, was significantly lower in the home-based group; these patients rated their satisfaction more often as "very satisfied". Most participants in both groups indicated they would prefer home-based phototherapy. QoL increased equally regardless of where the phototherapy was given, but patients treated at home rated their therapy as excellent more often than outpatients ( $42 \%$ vs $23 \%)$ ). On the other hand, patients treated with home-based phototherapy rated the waiting time as too long, more often than outpatients ( $26 \%$ vs $21 \%$ ).

Cameron et $\mathrm{al}^{10}$ performed a survey and a cohort study for the period 1998-2011. The clearance or MRA rates in patients treated with home-based NB-UVB phototherapy were studied. The results of outpatient UVB phototherapy in 2011 were used for comparison. Two hundred of the 249 studied therapy courses were regarding patients with psoriasis. Almost $75 \%$ of these patients achieved complete clearance or MRA with a mean number of 31 treatments, compared to $68 \%$ reaching MRA in a median of 29 exposures in the outpatient UVB phototherapy group.

Overall, patients reported to be very satisfied about home-based phototherapy. Results regarding effectivity on improvement in terms of disease severity and QoL were variable but generally positive.

An overview of characteristics of and results from studies evaluating the effectivity of home-based phototherapy vs outpatient phototherapy is presented in Table 1.

\section{What are the factors influencing the prescription of home-based phototherapy?}

If home-based phototherapy treatment is equally effective in most studies and patients seem to prefer this modality, why is its use not more widely spread? Abel ${ }^{4}$ and Sarkany et al ${ }^{11}$ pointed out in an expert opinion communication that the medical and legal responsibility of the patients' safety when treated with home-based phototherapy lies with the prescribing dermatologist. Problems could therefore occur in case of inadequate supervision. In many countries, once home-based phototherapy is prescribed, patients have unlimited access. Careful patient selection, careful instruction about the equipment, as well as a detailed treatment schedule, supervision, and monitoring are very important for successful treatment and patient safety. 


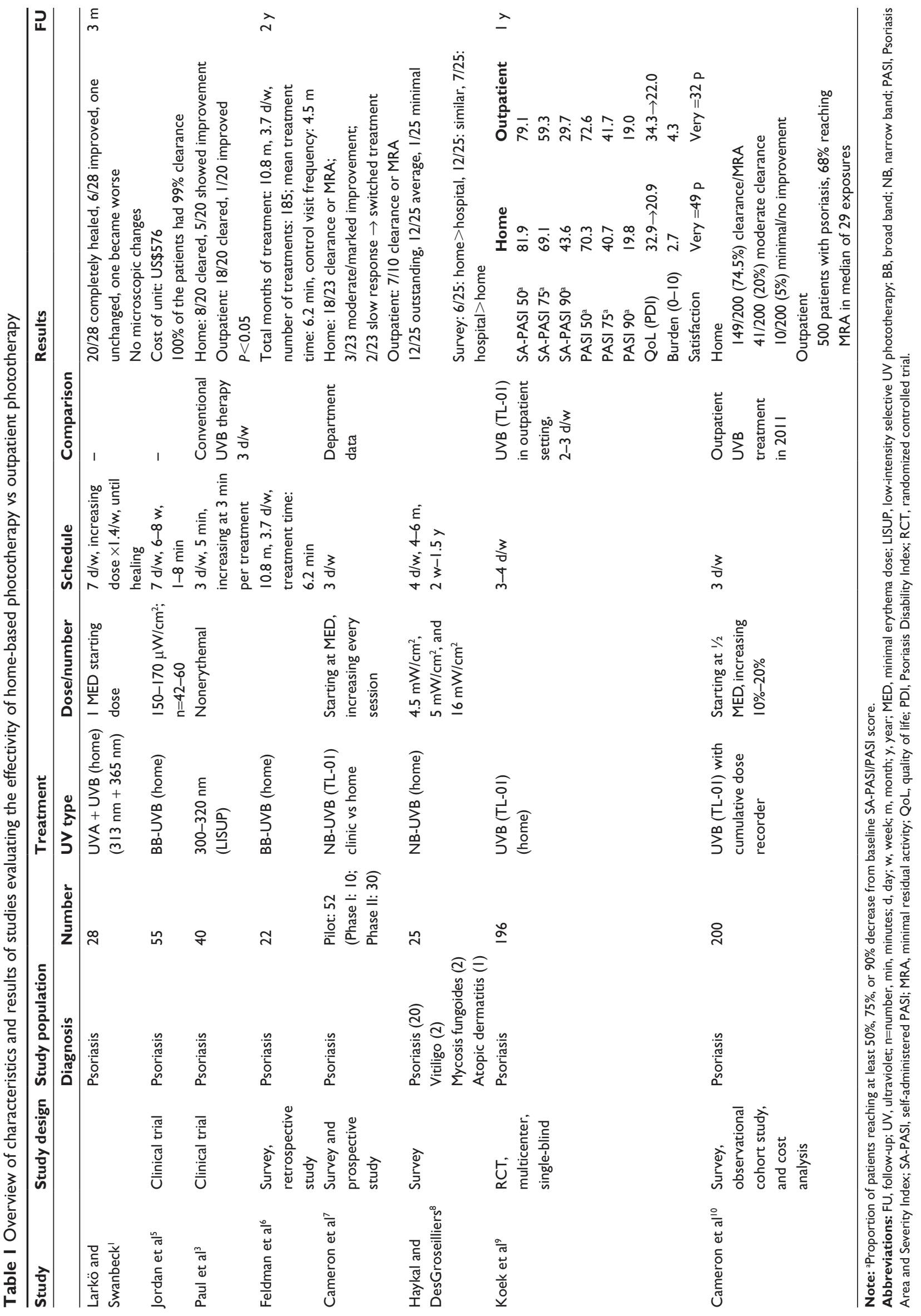


Feldman et $\mathrm{al}^{6}$ performed a survey among 31 patients with psoriasis treated with home-based phototherapy, of whom 22 responded. The patients bought a UVB phototherapy device of any kind, to use at home. Patients were very satisfied with homebased phototherapy. The authors found that these patients used phototherapy at a frequency and duration comparable to those described in existing guidelines. It is described that to achieve this level of compliance, significant physician time to select the appropriate patients and explain the treatment is needed. The authors found the mean time between follow-up visits to be too long, 4.5 months, when compared to the 3 months recommended by Lowe et al, ${ }^{12}$ and the equipment was never checked or partially replaced. Other concerns were the facts that patients have an "open prescription" for therapy and that the dose of UV irradiation received is poorly controlled. All these factors make prescribing home-based phototherapy a contentious issue.

Bhutani and $\mathrm{Liao}^{13}$ reviewed how to choose appropriate patients for home-based phototherapy and how to educate them, as well as summarizing the costs and designs of homebased phototherapy equipment. They obtained information through $>1$ decade of clinical experience at the University of California San Francisco Psoriasis and Skin Treatment Center and stated that ideal patients for home-based phototherapy were patients with widespread psoriasis for whom topical treatment was impractical or ineffective, who were not using photosensitizing medication, patients without skin cancer history, and patients who are reliable and for whom outpatient phototherapy is effective but impractical or impossible. They found that some dermatologists do not prescribe home-based phototherapy because of fear of inferior efficacy and higher risks. Selecting the right patients is an important step in the process of prescribing home-based phototherapy and this process improves the safety. The steps include a recording of history and physical examination of the patient, excluding contraindications, checking whether patients are reliable, and arranging for proper training of the patients. ${ }^{13}$

Sarkany et al ${ }^{11}$ suggested the use of an electronic "smart card" preprogrammed by the dermatologist, which could provide more control over the execution of treatment, as the dermatologist has medical and legal responsibility. This could minimize concerns about ongoing unsupervised phototherapy, use of the equipment by persons other than the patient, and other safety issues. A possible issue that remains is that patients have less contact with professionals and other patients.

Cameron et $\mathrm{al}^{7}$ addressed the responsibility issue in 2002 by requiring patients to provide signed informed consent forms about the guidelines regarding phototherapy. Patients also had to keep records of their home-based phototherapy treatment. They found that these patients were able to keep good records and reported lesser travel time and distance, as well as lower costs and loss of income, than when undergoing phototherapy in an outpatient setting. The home phototherapy units were owned and maintained by the hospital department. In 2014, Cameron et a ${ }^{10}$ analyzed the Tayside home phototherapy database for the period from 1998 to 2011 and found that 140 out of 160 patients (87.5\%) prefer home-based phototherapy over outpatient phototherapy, although they recorded longer waiting times (2-3 months for home-based phototherapy compared to $<6$ weeks for outpatient phototherapy). For home-based phototherapy to be possible, safe, and effective, patients must be able to operate the equipment, have suitable space in their home, commit to training, and follow treatment guidelines. Improving education for dermatologists could increase understanding and reduce anxiety about home-based phototherapy; this might lead to higher prescription rates of home-based phototherapy.

Koek et a ${ }^{14}$ performed a literature and guideline search on home-based phototherapy for patients with psoriasis and conducted a survey among dermatologists from 32 countries all over the world, but mainly the Netherlands, in 2006 and found some discrepancies. As already mentioned, the medicolegal responsibility is a commonly discussed subject. In the responses to the survey questions among dermatologists, however, it was scarcely mentioned. The main reasons found in favor of home-based phototherapy were lesser time and travel distance, convenience, reduced medicalization, and lower costs. The reasons for reluctance to home treatment were lack of medical supervision, higher risks, and uncontrolled use of equipment after the treatment period. A common problem is noncompliance. This could raise problems, especially in the case of home-based phototherapy.

Yentzer et $a 1^{15}$ performed a clinical trial to examine patients' adherence to acitretin compared to adherence to home-based phototherapy. Adherence to acitretin was monitored using an electronic monitoring medication bottle cap and adherence to phototherapy by a light-sensing data logger; 22 out of 27 patients with psoriasis completed the 12-week trial. The mean adherence to acitretin decreased steadily, with -0.24 uses every week; only one patient was $100 \%$ adherent to acitretin. The mean adherence to home-based phototherapy remained steady, however.

Haykal and DesGroseilliers ${ }^{8}$ performed a survey on NB-UVB use at home among 25 patients with photoresponsive diseases; $80 \%$ of these patients had psoriasis. 
The main reasons for choosing home-based phototherapy were less travel expenses, time required, and difficulties with work schedule, as well as positive recommendations by the dermatologist. The authors stressed the importance of regular supervision but were unable to motivate patients to fix regular appointments. Only one out of 25 patients had follow-up visits every 3 months, eleven out of 25 every 6 months, three out of 25 once a year, and nine out of 25 had no follow-up planned at all. The exact reasons are unclear, but it seems that the patients missed or neglected (making) the appointments.

Yarbrough et $\mathrm{al}^{16}$ assessed the posttrial ${ }^{15}$ use of homebased phototherapy equipment by patients with psoriasis, without a specific protocol for treatment. During the original trial of Yentzer et al, ${ }^{15}$ patients were treated with NB-UVB at home three times weekly for 12 weeks. After the trial, subjects were told they could continue to use the devices for maintenance purposes. The devices were equipped with dose-measuring equipment. They found no excessive use at all. Their study ${ }^{16}$ thus provides additional support for the safety of home-based phototherapy devices, especially those equipped with controlled prescription timers as used in the study.

Yentzer and Feldman ${ }^{17}$ conducted a database search and survey among patients and dermatology residents. Fortythree percent of the patients with a home-based phototherapy prescription did not purchase their device; in 73\% of these cases, the reason was high out-of-pocket expenses. Homebased phototherapy is cost-effective but in the US, patients have mentioned high out-of-pocket expenses. ${ }^{18}$ Only $35 \%$ of the dermatology residents surveyed received formal training on home-based phototherapy. The main reasons for dermatologists not prescribing home-based phototherapy were fear for high patient costs and frustration about the reimbursement policy of insurance companies. Twenty percent of respondents were unaware of the existence of home-based phototherapy or did not know how to prescribe it.

Lumley et $\mathrm{al}^{19}$ found in a semistructured interview among patients with psoriasis and dermatology health care professionals in the UK that all of the interviewed dermatology health care professionals had poor understanding of home-based phototherapy and that some had skepticism. Patients and nurses were more positive about home-based phototherapy than dermatologists.

Dothard et $\mathrm{al}^{20}$ investigated the reasons for not purchasing a prescribed home UV unit by conducting a telephone survey among 163 patients with psoriasis to whom home-based phototherapy was prescribed but who chose other therapy options. Thirty-one percent of the patients reported to prefer biologic agents; other reasons were high costs (18\%) and no insurance coverage (17\%).

\section{Costs}

An important consideration in the implementation of homebased phototherapy is the financial aspect.

Feldman et $\mathrm{al}^{6}$ stated that the average one-time cost of a home phototherapy device in 1996 in the US was $<\$ 1,500$. They estimated the cost per treatment session to be $<\$ 10$, based on an average of 185 treatments in the 2 years prior to the study and on the assumption that the unit is amortized over 1 year. They did not compare it to the costs of outpatient phototherapy and did not include the costs for the dermatology department and the cost for follow-up visits; it is the sheer cost of equipment.

Cameron et $\mathrm{al}^{7}$ compared the costs of one treatment course of home-based phototherapy with outpatient phototherapy in the UK in 2002 and divided these costs into costs to the patient and cost to the hospital. Patients gave detailed information about travel costs, loss of earnings, payment to receive the home phototherapy device, childcare, and other expenses. They found that for the patients, home-based phototherapy was less expensive; $£ 128$ compared to $£ 189$ for outpatient phototherapy. For the hospital, however, homebased phototherapy was more expensive; $£ 112$ compared to $£ 89$ for outpatient phototherapy. The total costs for society, hospital, and patient are not significantly different: $£ 240$ for home-based phototherapy and $£ 278$ for outpatient phototherapy. In 2014 , Cameron et $\mathrm{l}^{10}$ made a new cost analysis and found that the total costs for society had increased to $£ 410$ for home-based phototherapy and $£ 550$ for outpatient phototherapy. The reason for the increase of patients' expenses in case of outpatient phototherapy could be that the range of expenses reported by patients was $£ 0-£ 19.736$. Looking at the average costs with this excessive range gives a distorted image. For patients, home-based phototherapy was much less expensive than outpatient phototherapy; for hospitals, however, this was vice versa.

Yelverton et $\mathrm{al}^{21}$ stated in 2006 in the USA that the costs from a third-party payer perspective of 30-year treatment with home-based NB-UVB are $\sim \$ 7,000$, compared to $\$ 37,000$ for psoralen with ultraviolet A, $\$ 19,000$ for methotrexate, $\$ 75,000$ for acitretin, and an average of $\$ 250,000$ for one of the three different biologics included in the study. They found that within 2 years of treatment initiation, homebased phototherapy, including purchase of the equipment, bulb replacement, and control visits every 3 months, is less 
costly than any other treatment examined. Home-based phototherapy costs are the highest at initiation because of the initial costs of equipment. According to Bhutani and Liao, ${ }^{13}$ costs of home-based phototherapy equipment in 2010 in the USA varied between $\$ 2,180$ and $\$ 7,000$, depending on the size and design.

Sixteen out of 25 patients in the survey of Haykal and DesGroseilliers $^{8}$ reported having monthly savings varying from $\$ 20$ to $\$ 600$ when undergoing phototherapy at home compared to the outpatient setting. The amount of savings was dependent on the travel distance from their homes to the hospital.

Another aspect of the costs of home-based phototherapy is the coverage by insurance companies. Yentzer et $\mathrm{al}^{22}$ reviewed three large insurance companies in the US in 2009 regarding the reimbursement of home-based phototherapy compared to treatment with biologic drugs. They found that insurance companies vary widely in their coverage policies. Home-based phototherapy is very difficult to get approved compared to outpatient phototherapy and biologics. Requirements for coverage of home-based phototherapy are much more stringent than those for biologics, while home-based phototherapy is much less expensive than treatment with any biologic, especially after the first year when the phototherapy equipment is already purchased.

Yentzer and Feldman ${ }^{17}$ found that the out-of-pocket costs for patients to initiate home-based phototherapy are around $\$ 2,000$. Even when partly covered by their health insurance, the costs to the patient remain at $>\$ 1,000$, and this is often more than can be afforded.

The study about the cost-effectivity of home-based phototherapy compared to outpatient phototherapy by Koek et al ${ }^{18}$ in 2010 suggests that home-based phototherapy is slightly more beneficial in terms of the gain of quality-adjusted life years (QALYs) (0.2960 for home-based phototherapy versus 0.2908 for outpatient phototherapy; difference $=0.0052$ ), but also slightly more expensive (€800 for home-based phototherapy versus $€ 752$ for outpatient phototherapy; difference $=€ 48) .{ }^{18}$ The overall costs for one course of treatment were calculated by multiplying the mean use of resources (including treatments, consultation, traveling, parking, and reduced productivity) by the mean costs of these resources. They calculated incremental cost-effectivity ratio (ICER) by dividing the difference in costs $(€ 48)$ by the difference in gain of QALYs (0.0052). The ICER indicates the costs per QALY gained when switching from outpatient phototherapy to home-based phototherapy. These costs per QALY gained are $€ 9,276$ when viewed directly after the end of the phototherapy treatment (mean: 17.6 weeks after $t=0$ ). They also calculated overall costs, gained QALYs, and ICER at 1 year after the end of phototherapy (mean: 68.4 weeks after $t=0$ ). This ICER was only $€ 4,646$. Both ICERs remained far below the policy of a maximum cost of $€ 20,000$ per QALY gained.

Vañó-Galván et $\mathrm{al}^{23}$ performed a retrospective costeffectivity study in 2012 in Spain. They included 12 patients with psoriasis and compared the cost-effectivity of home-based NB-UVB phototherapy compared to that of biologic drugs. They found that achieving PASI-75 is much less expensive when patients were treated with home-based phototherapy (€903) than when patients were treated with biologics $(€ 8,256)$. PASI-75 was achieved in five out of the six patients treated with biologics and in four out of the six patients treated with home-based phototherapy. Notable is that this was a retrospective study and the choice of treatment was not randomized.

Yentzer et $\mathrm{al}^{24}$ made a cost analysis in 2013 of the expenses for the patient undergoing outpatient phototherapy three times a week for a period of 3 months. They estimated the costs of commuting, including travel costs, lost wages, copayment, and car maintenance and determined when it was cost-effective to purchase a home-based phototherapy unit, which costs $\sim \$ 2,600$ on average. The total costs of commuting incurred by the patient when having to travel $16.1 \mathrm{~km}$ (10 miles) to the phototherapy location are $\$ 1,871$; for $32.2 \mathrm{~km}$ (20 miles), this was $\$ 2,620$, and for $80.5 \mathrm{~km}$ (50 miles), it was $\$ 4,864$. They concluded that for patients living $32.2 \mathrm{~km}$ (20 miles) or further away from the outpatient phototherapy location, it was cost-effective to purchase a home-based phototherapy unit even without reimbursement.

A detailed summary of all cost analyses is provided in Table 2.

\section{Discussion}

Although the studies on home-based phototherapy were mostly conducted with BB-UVB, more recent studies have been performed with NB-UVB. ${ }^{7,9,14,18}$ The results of both modalities show that home-based phototherapy is effective and patients often prefer this treatment modality over treatment in the outpatient clinic. This raises the question: Why it is not prescribed more often?

In this review, different aspects of home-based phototherapy in the treatment of psoriasis are reviewed. Publications regarding this subject were found to be very heterogeneous, making it difficult to compare the results. Results of studies performed with BB-UVB carried out at home cannot be directly compared with later studies 
Table 2 Overview of characteristics and results of studies evaluating the costs of home-based phototherapy vs outpatient phototherapy and other therapies

\begin{tabular}{|c|c|c|c|c|c|c|}
\hline \multirow{2}{*}{$\frac{\text { Study (ref) }}{{\text { Feldman et } \mathrm{al}^{6}}^{6}}$} & \multirow{2}{*}{$\begin{array}{l}\text { Study design } \\
\text { Survey }\end{array}$} & \multirow{2}{*}{$\begin{array}{l}\text { Study population } \\
22 \text { patients with } \\
\text { psoriasis }\end{array}$} & \multicolumn{4}{|l|}{ Results } \\
\hline & & & \multicolumn{4}{|c|}{ One-time cost: US\$1,500 } \\
\hline Cameron et $\mathrm{al}^{7}$ & Patient questionnaires & $\begin{array}{l}52 \text { patients with } \\
\text { psoriasis }\end{array}$ & $\begin{array}{l}\text { Home } \\
\text { Patient costs: } \\
\qquad \mid 28\end{array}$ & $\begin{array}{l}\text { Hospital costs: } \\
\qquad \mid 12\end{array}$ & $\begin{array}{l}\text { Outpatient } \\
\text { Patient costs: } \\
\qquad 189\end{array}$ & $\begin{array}{l}\text { Hospital costs: } \\
\qquad 89\end{array}$ \\
\hline Cameron et al ${ }^{10}$ & $\begin{array}{l}\text { Analysis of the Tayside home } \\
\text { phototherapy database between } \\
\text { the years } 1998 \text { and } 201 \text { I, patient } \\
\text { questionnaires }\end{array}$ & $\begin{array}{l}212 \text { patients with } \\
\text { psoriasis or atopic } \\
\text { dermatitis }\end{array}$ & $\begin{array}{l}\text { Home } \\
\text { Patient costs: } \\
£ \mid 37\end{array}$ & $\begin{array}{l}\text { Hospital costs: } \\
£ 270\end{array}$ & $\begin{array}{l}\text { Outpatient } \\
\text { Patient costs: } \\
£ 438\end{array}$ & $\begin{array}{l}\text { Hospital costs: } \\
\text { }|| 4\end{array}$ \\
\hline Yelverton et $\mathrm{al}^{21}$ & $\begin{array}{l}\text { 30-year treatment cost analysis } \\
\text { of NB-UVB compared with } \\
\text { PUVA, MTX, acitretin, and three } \\
\text { biologics }\end{array}$ & $\begin{array}{l}\text { Patients with severe } \\
\text { psoriasis }\end{array}$ & $\begin{array}{r}\text { Cost of a } 30- \\
\text { Home PT: } \$ \\
\text { MTX: } \$ 19,1 \\
\text { PUVA: } \$ 37,5 \\
\text { Acitretin: } \$ 7 \\
\text { Biologics (av }\end{array}$ & $\begin{array}{l}\text { ar course } \\
885.27 \\
36 \\
\text { l. } 46 \\
\text { I } 12.69 \\
\text { age): } \$ 257,559.25\end{array}$ & & \\
\hline \multirow[t]{3}{*}{ Yentzer et $\mathrm{a}^{22}$} & $\begin{array}{l}\text { Trial of } 3 \text { months home } \\
\text { phototherapy before prescribing } \\
\text { biologics }\end{array}$ & Psoriasis & \multicolumn{2}{|l|}{ Annual costs } & $\begin{array}{l}\text { Outpatient } \\
\text { PT }\end{array}$ & Biologics \\
\hline & & & Patient & $\begin{array}{l}\$ 2,590 \\
\text { (only first year) }\end{array}$ & $\$ 3,040$ & $\$ 920$ \\
\hline & & & company & $\$ 5$ & $\$ 76$ & $\$ 23,408$ \\
\hline Koek et al $\left.\right|^{18}$ & $\begin{array}{l}\text { Cost analysis of home-UVB } \\
\text { PT compared to UVB PT in } \\
\text { an outpatient setting from the } \\
\text { societal perspective }\end{array}$ & $\begin{array}{l}196 \text { patients with } \\
\text { psoriasis }\end{array}$ & \multicolumn{2}{|c|}{ Society costs of home PT: $€ 800$} & $\begin{array}{l}\text { Society costs o } \\
€ 752 \\
\text { Gain of QALYS } \\
\text { Costs per QAL }\end{array}$ & $\begin{array}{l}\text { outpatient PT: } \\
0.296 \\
\text { gained: } € 4,646\end{array}$ \\
\hline $\begin{array}{l}\text { Vañó-Galván } \\
\text { et a }{ }^{23}\end{array}$ & $\begin{array}{l}\text { Retrospective cost-effectivity } \\
\text { study comparing direct costs and } \\
\text { PASI-75 of home-UVB therapy } \\
\text { and biologic drugs in Spain }\end{array}$ & $\begin{array}{l}12 \text { patients with } \\
\text { psoriasis }\end{array}$ & $\begin{array}{r}\text { Costs of achi } \\
\text { Biologic ager } \\
\text { Home PT: } €\end{array}$ & $\begin{array}{l}\text { ing PASI-75 with } \\
€ 8,256 \\
3\end{array}$ & & \\
\hline Yentzer et $\mathrm{al}^{24}$ & $\begin{array}{l}\text { Analyzing the travel costs plus } \\
\text { lost wages vs cost of home PT } \\
\text { equipment }\end{array}$ & Psoriasis & $\begin{array}{r}\$ 2,600 \text { per ave } \\
\text { Total costs for } \\
\text { living } 10 \text { mile } \\
\text { living } 20 \text { mile } \\
\text { living } 50 \text { mile }\end{array}$ & $\begin{array}{l}\text { ge home PT unit } \\
\text { atient for } 3 \text { months } \\
\text { from clinic: } \$ 1,87 \text { I } \\
\text { from clinic: } \$ 2,620 \\
\text { from clinic: } \$ 4,864\end{array}$ & of outpatient PT & hen \\
\hline
\end{tabular}

Abbreviations: NB-UVB, narrow band ultraviolet B; PUVA, psoralen + UVA; MTX, methotrexate; PT, phototherapy; QALY, quality-adjusted life years; PASI, Psoriasis Area and Severity Index; PASI-75, proportion of patients reaching at least 75\% decrease from baseline PASI-score.

conducted with NB-UVB at home or in the outpatient clinic. Double-blind or even placebo-controlled effectivity trials were not available.

In the treatment for psoriasis, home-based phototherapy seems equally effective and safe as phototherapy in the outpatient setting. ${ }^{9,10}$ The QoL of patients improves regardless of the modality, but patients were more satisfied with home-based phototherapy compared to outpatient phototherapy. ${ }^{8,9}$ The journey to the clinic several times a week leads to greater burden. Home-based phototherapy seems to be a good alternative. Many factors play a role in the decision whether a patient will be prescribed homebased phototherapy. The factors that negatively influence the prescription of or choice for home-based phototherapy mentioned in the included studies can be summarized as lack of knowledge, lack of control, and lack of an adequate reimbursement system.

In a study by Yentzer and Feldman, ${ }^{17} 20 \%$ of responding dermatology residents were unaware of the existence of home-based phototherapy. Thirty-five percent did not receive formal training in home-based phototherapy treatment. These numbers are high when considering that home-based phototherapy was introduced around the year 1979.

To enhance the availability of phototherapy for patients, it is important that more dermatologists are aware of the effectivity and safety profile of phototherapy. Focus in this regard should also be given during the training of Dermatology residents, as they are the dermatologists of the future. 
When dermatologists are aware of this treatment option, several other points of concern arise, sometimes preventing prescription: skepticism about effectivity, ${ }^{19}$ as well as safety aspects, legal aspects, and the associated costs.

The costs in most studies are accounted for as a break even for society, but every country, and sometimes even every health insurance company, has its own reimbursement policy. ${ }^{18,24}$ The costs for individual patients and hospitals vary greatly, even within a country.

As every country has its own health insurance and reimbursement system, it is hard to generalize a conclusion to facilitate prescription from a cost aspect. Dermatologists and patient fora should however be aware of the possibilities in their own respective country. An open discussion with the patient about those possibilities and the potential concerns of dermatologists regarding home-based treatment might facilitate the selection of the right patients for this treatment modality.

Phototherapy is an effective treatment for the skin symptoms in psoriasis. It is a good treatment option for localized disease and should be considered before use of systemic immunosuppressants such as methotrexate, cyclosporine, and biologic drugs. Treatment with biologic drugs for psoriasis is widely and readily reimbursed, as opposed to phototherapy. Although biologic drugs do address the systemic aspects of psoriasis, home-based phototherapy is cheaper than treatment with biologic drugs such as tumor necrosis factor- $\alpha$ inhibitors. ${ }^{22}$ Although systemic medication can be easier to prescribe and compliance is easier to achieve, the low risk of systemic side effects and the specificity of the administration site, ie, the skin, during treatment with phototherapy should be taken into consideration. Phototherapy is an effective, cheap treatment option, but it can be time consuming in the outpatient setting. In the home-based setting, careful patient selection remains important to minimize the associated concerns and optimize adherence to the personalized treatment protocol.

As in Western countries, the burden of health expenses is increasing further; every health care professional should try to prescribe the most effective treatment considering the costs. Lenience from the insurance companies in this regard is of utmost importance, for the benefit of patients as well as society.

Phototherapy with ultraviolet light is an established and broadly studied treatment option for psoriasis. Although there is lack of uniformity in study designs, several high-quality studies that demonstrate the efficacy of phototherapy at home as well as in the outpatient setting have been performed. ${ }^{1,7,9}$ Reluctance and unfamiliarity regarding home-based phototherapy should be countered with high-quality studies and education.

Although there is still some reluctance regarding homebased phototherapy, recent new developments in light-based treatment have been described. ${ }^{25,26}$ Among them are low-dose home UVB in the shower, which has shown effectivity in mild-to-moderate psoriasis, and portable blue light-emitting diodes, which resulted in clinical improvement in patients with isolated psoriasis plaques. ${ }^{25,26}$ Further treatment modalities will include the use of laser devices targeting specific wavelengths with biological effects.

All these initiatives will hopefully make treatment with distinct light-emitting devices more easily available for home-based treatment.

\section{Disclosure}

The department of Dermatology of VU Medical Centre received funding to study the effects of low-emission phototherapy from Dermasun Medical BV. The authors report no other conflicts of interest in this work.

\section{References}

1. Larko O, Swanbeck G. Home solarium treatment of psoriasis. $\mathrm{Br} J$ Dermatol. 1979;101:13-16.

2. Franken SM, Witte B, Pavel S, Rustemeyer T. Psoriasis and daily low-emission phototherapy: effects on disease and vitamin D level. Photodermatol Photoimmunol Photomed. 2015;31(2):83-89.

3. Paul BS, Stern RS, Parrish JA, Arndt KA. Low-intensity selective UV phototherapy. A clinical trial in outpatient therapy for psoriasis. Arch Dermatol. 1983;119:122-124.

4. Abel EA. Considerations in the use of home ultraviolet radiation therapy for psoriasis. Cutis. 1985;35:127-128.

5. Jordan WP Jr, Clarke AM, Hale RK. Long-term modified Goeckerman regimen for psoriasis using an ultraviolet B light source in the home. J Am Acad Dermatol. 1981;4:584-591.

6. Feldman SR, Clark A, Reboussin DM, Fleischer AB, Jr. An assessment of potential problems of home phototherapy treatment of psoriasis. Cutis. 1996;58:71-73.

7. Cameron H, Yule S, Moseley H, Dawe RS, Ferguson J. Taking treatment to the patient: development of a home TL-01 ultraviolet B phototherapy service. Br J Dermatol. 2002;147:957-965.

8. Haykal KA, DesGroseilliers JP. Are narrow-band ultraviolet B home units a viable option for continuous or maintenance therapy of photoresponsive diseases? J Cutan Med Surg. 2006;10:234-240.

9. Koek MB, Buskens E, van WH, Steegmans PH, Bruijnzeel-Koomen CA, Sigurdsson V. Home versus outpatient ultraviolet B phototherapy for mild to severe psoriasis: pragmatic multicentre randomised controlled non-inferiority trial (PLUTO study). BMJ. 2009;338:b1542.

10. Cameron H, Yule S, Dawe RS, Ibbotson SH, Moseley H, Ferguson J. Review of an established UK home phototherapy service 1998-2011: improving access to a cost-effective treatment for chronic skin disease. Public Health. 2014;128:317-324.

11. Sarkany RP, Anstey A, Diffey BL, et al. Home phototherapy: report on a workshop of the British Photodermatology Group, December 1996. Br J Dermatol. 1999;140:195-199.

12. Lowe NJ, Prystowsky JH, Bourget T, Edelstein J, Nychay S, Armstrong R Acitretin plus UVB therapy for psoriasis. Comparisons with placebo plus UVB and acitretin alone. J Am Acad Dermatol. 1991;24:591-594. 
13. Bhutani T, Liao W. A practical approach to home UVB phototherapy for the treatment of generalized psoriasis. Pract Dermatol. 2010;7:31-35.

14. Koek MB, Buskens E, Bruijnzeel-Koomen CA, Sigurdsson V. Home ultraviolet $\mathrm{B}$ phototherapy for psoriasis: discrepancy between literature, guidelines, general opinions and actual use. Results of a literature review, a web search, and a questionnaire among dermatologists. $\mathrm{Br} \mathrm{J}$ Dermatol. 2006;154:701-711.

15. Yentzer BA, Yelverton CB, Pearce DJ, et al. Adherence to acitretin and home narrowband ultraviolet B phototherapy in patients with psoriasis. J Am Acad Dermatol. 2008;59:577-581.

16. Yarbrough C, Yentzer BA, Yelverton CB, Feldman SR. Continued use of home narrowband ultraviolet B light phototherapy for psoriasis after completion of a clinical trial. J Am Acad Dermatol. 2009;60:877-879.

17. Yentzer BA, Feldman SR. Trends in home phototherapy adoption in the US: monetary disincentives are only the tip of the iceberg. J Dermatolog Treat. 2011;22:27-30.

18. Koek MB, Sigurdsson V, van WH, Steegmans PH, BruijnzeelKoomen CA, Buskens E. Cost effectiveness of home ultraviolet B phototherapy for psoriasis: economic evaluation of a randomised controlled trial (PLUTO study). BMJ. 2010;340:c1490.

19. Lumley S, Salako K, Anstey AV. Evaluation of patients' and healthcare professionals' knowledge and views about home phototherapy; Liverpool, 2013. [Ref Type: Report].
20. Dothard EH, Sandoval LF, Yentzer BA, Feldman SR. Home ultraviolet light therapy for psoriasis: why patients choose other options. Dermatol Online J. 2015;21:11.

21. Yelverton CB, Kulkarni AS, Balkrishnan R, Feldman SR. Home ultraviolet B phototherapy: a cost-effective option for severe psoriasis. Manag Care Interface. 2006;19(33-36):39.

22. Yentzer BA, Yelverton CB, Simpson GL, et al. Paradoxical effects of cost reduction measures in managed care systems for treatment of severe psoriasis. Dermatol Online J. 2009;15:1.

23. Vano-Galvan S, Garate MT, Fleta-Asin B, et al. Análisis coste-efectividad de la fototerapia domiciliaria con ultravioleta B de banda estrecha frente a fármacos biológicos en el tratamiento de la psoriasis moderadagrave [Analysis of the cost effectiveness of home-based phototherapy with narrow-band UV-B radiation compared with biological drugs for the treatment of moderate to severe psoriasis]. Actas Dermosifiliogr. 2012;103:127-137. Spanish.

24. Yentzer BA, Gustafson CJ, Feldman SR. Explicit and implicit copayments for phototherapy: examining the cost of commuting. Dermatol Online J. 2013;19:18563.

25. Pfaff S, Liebmann J, Born M, Merk HF, von Felbert V. Prospective randomized long-term study on the efficacy and safety of UV-free blue light for treating mild Psoriasis vulgaris. Dermatology. 2015;231:24-34.

26. Weinstabl A, Hoff-Lesch S, Merk HF, von Felbert V. Prospective randomized study on the efficacy of blue light in the treatment of psoriasis vulgaris. Dermatology. 2011;223:251-259.
Psoriasis: Targets and Therapy

\section{Publish your work in this journal}

Psoriasis: Targets and Therapy is international, peer-reviewed, open access journal focusing on psoriasis, nail psoriasis, psoriatic arthritis and related conditions, identification of therapeutic targets and the optimal use of integrated treatment interventions to achieve improved outcomes and quality of life. The manuscript management system

\section{Dovepress}

is completely online and includes a very quick and fair peer-review system. Visit http://www.dovepress.com/testimonials.php to read real quotes from published authors. 